\section{Commentary: Robotic first rib resection: A safe, modern update}

\author{
Brian Housman, MD, and Raja M. Flores, MD
}

In their manuscript "Safety of Robotic First Rib Resection for Thoracic Outlet Syndrome," Burt and colleagues ${ }^{1}$ present an efficient, robotic-assisted technique and compare it with an open supraclavicular procedure performed by a single surgeon. The technical differences between the open and robotic techniques are substantial. ${ }^{2,3}$ In brief, supraclavicular first rib exposure requires mobilization of the sternocleidomastoid, scalene muscles, phrenic nerve, subclavian artery, vein, and the brachial plexus. ${ }^{4}$ The robotic technique uses three 8-mm ports and achieves immediate visualization upon entry into the chest. The rib can be mobilized and removed with minimal dissection of involved muscle and without retraction of neurovascular structures. $^{2}$

Historically, multiple procedures were developed to treat thoracic outlet syndrome, including anterior scalene muscle division, claviculectomy, and the posterior, supraclavicular, transaxillary, thoracoscopic, and robotic approaches to first rib resection. ${ }^{2,4,5}$ Safety has been a focus of research at least since "Dale's Report" in 1982, which was unable to clearly identify the best contemporary intervention. ${ }^{5}$ Complications have included, and are not limited to, pneumothorax, causalgia, lymphatic leak, and injury to the subclavian vasculature, long thoracic nerve, and brachioplexus., With improvements in diagnostic testing and endoscopic instrumentation, the role of minimally invasive first rib resections have become increasingly popular. ${ }^{2}$

Burt and colleagues present their series of 123 first rib resections; 51 via a supraclavicular approach and 72 with robotic assistance. The published technique boasts superior

\footnotetext{
From the Department of Thoracic Surgery, Icahn School of Medicine at Mount Sinai, Mount Sinai Health System, New York, NY.

Disclosures: The authors reported no conflicts of interest.

The Journal policy requires editors and reviewers to disclose conflicts of interest and to decline handling or reviewing manuscripts for which they may have a conflict of interest. The editors and reviewers of this article have no conflicts of interest.

Received for publication Oct 5, 2020; revisions received Oct 5, 2020; accepted for publication Oct 6, 2020; available ahead of print Oct 13, 2020.

Address for reprints: Raja M. Flores, MD, Mount Sinai Health System, Icahn School of Medicine at Mount Sinai, One Gustave L. Levy Place, Box 1023, New York, NY 10029 (E-mail: raja.flores@mountsinai.org).

J Thorac Cardiovasc Surg 2021;162:1306-7

0022-5223/ $\$ 36.00$

Copyright $₫ 2020$ Published by Elsevier Inc. on behalf of The American Association for Thoracic Surgery

https://doi.org/10.1016/j.jtcvs.2020.10.019
}

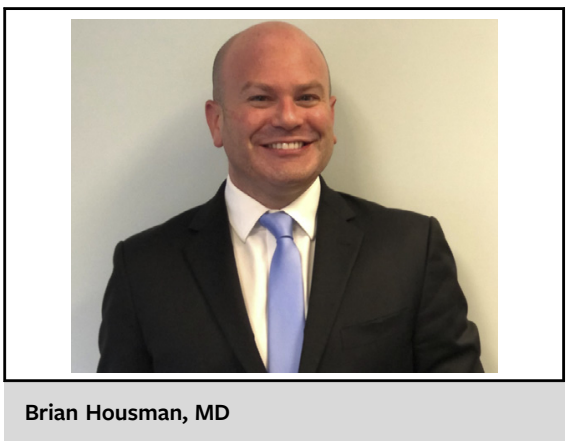

CENTRAL MESSAGE

The authors present a safe, efficient technique for first rib resection that makes a historically complex procedure widely available to surgeons with robotic experience.

exposure, reduces technical steps, avoids division of strap muscles, and minimizes contact with neurovascular structures. ${ }^{4}$ As a result, it increases technical efficiency and reduces the rates of complications. The authors found it lowers pain scores and postoperative opioid use and is associated with a decreased rate of brachial plexus palsies $(18 \%$ vs $1 \%$ ), phrenic nerve injury ( $6 \%$ vs $1 \%$ ), and chyle leak $(4 \%$ vs $0 \%)$.

The modern application of the robotic approach for first rib resection has been shown to be safe, even with a limited surgeon experience. ${ }^{2,3}$ Since the authors performed most robotic procedures toward the end of the series, they reemphasize a short learning curve and early improvement in outcomes. With the widespread use of the Xi platform, surgeons will probably be more comfortable with thoracoscopic exposure than supraclavicular dissection. Even if lower-volume centers cannot achieve the same results, patients will likely benefit from improved visualization and streamlined operative steps.

The authors should be applauded on an excellent technique that will help modernize this procedure and make it a surgical option in any hospital with robotic resources.

\section{References}

1. Burt BM, Palivela N, Cekmecelioglu D, Paily P, Najafi B, Lee H-S, et al. Safety of robotic first rib resection for thoracic outlet syndrome. J Thorac Cardiovasc Surg. 2021;162:1297-305.e1.

2. Pupovac SS, Lee PC, Zeltsman D, Jurado J, Hyman K, Singh V. Robotic-assisted first rib resection: our experience and review of the 
literature. Semin Thorac Cardiovasc Surg. May 21, 2020 [Epub ahead of print].

3. Kocher GJ, Zehnder A, Lutz JA, Schmidli J, Schmid RA. First rib resection for thoracic outlet syndrome: the robotic approach. World J Surg. 2018;42:3250-5.
4. Donahue DM. Supraclavicular first rib resection. Op Tech Thorac Cardiovasc Surg. 2011;16:252-66.

5. Dale WA. Thoracic outlet compression syndrome. Critique in 1982. Arch Surg. 1982;117:1437-45.
See Article page 1297.

\section{Commentary: Just do it... robotically!}

John F. Lazar, MD

Every so often a generational evolution in technology catalyzes a specialty's armamentarium. Before the mid-2000s open prostatectomy was considered a morbid and bloody procedure. It was radically transformed into among the most common and safest procedures performed by urology specialists' adoption of robotics. Let's not forget the byproduct of this adoption just happened to launch the multibillion-dollar industry of digital surgery.

In no way am I suggesting that minimally invasive robotic first rib resection (R-FRR) for thoracic outlet syndrome (TOS) is going to transform surgery, but it is a stunning example of how a morbid procedure can be transformed into a safe, easy operation by an evolution in technology. Burk and colleagues ${ }^{1}$ discuss the safety of R-FRR for TOS makes a resounding argument that we should just do it... robotically!

Three aspects of this article establish their understanding of the procedure and separate it from prior publications: a detailed presentation of their open prospectively collected FRR data, equally detailed comparison of their subsequent R-FRR, create an extremely well-organized review of all FRR series with a minimum of 50 patients whom they then use to establish the safety of the R-FRR.

\footnotetext{
From the Division of Thoracic Surgery, Department of Surgery, MedStar Georgetown University Hospital, Washington, DC.

Disclosures: The author reported no conflicts of interest.

The Journal policy requires editors and reviewers to disclose conflicts of interest and to decline handling or reviewing manuscripts for which they may have a conflict of interest. The editors and reviewers of this article have no conflicts of interest.

Received for publication Oct 1, 2020; revisions received Oct 1, 2020; accepted for publication Oct 1, 2020; available ahead of print Oct 9, 2020.

Address for reprints: John F. Lazar, MD, Division of Thoracic Surgery, Department

Surgery, MedStar Georgetown University Hospital, Washington, DC 20010

(E-mail: John.f.lazar@medstar.net).

J Thorac Cardiovasc Surg 2021;162:1307-8

$0022-5223 / \$ 36.00$

Copyright (c) 2020 by The American Association for Thoracic Surgery

https://doi.org/10.1016/j.jtcvs.2020.10.003
}

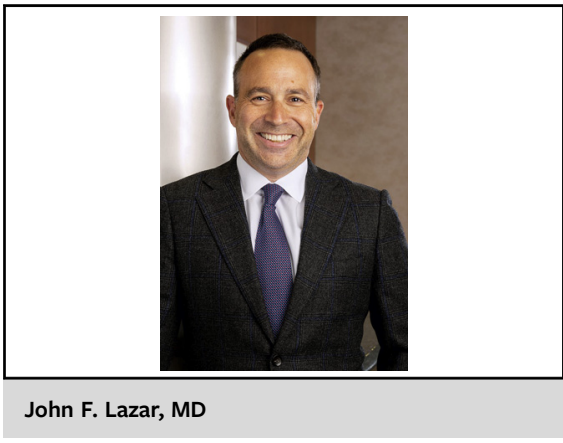

CENTRAL MESSAGE

Thoracic outlet syndrome can be an extremely challenging disease to diagnosis, but if you are going to operate, a robotic first rib section should be considered the gold standard.

It may be easy to conceive how a minimally invasive approach from the chest for FRR is superior to an open approach as the first rib is easily visualized and requires no manipulation of the vessel and nerve behind it. This obviates the need to mobilize the subclavian artery and the branchial plexus through the neck and injuring the brachial plexus. A minimally invasive approach also significantly reduces postoperative pain. Yet, unlike other articles comparing minimally invasive approaches, Burk and colleagues ${ }^{1}$ are able to demonstrate not all minimally invasive approaches are equal in their safety profile. They show that $\mathrm{R}$-FRR in comparison to thoracoscopy is superior in reduction of brachial plexus and long thoracic nerve injury, hemothorax, pneumothorax, chyle leak, and re-exploration when compared with prior studies. ${ }^{2-4}$

Although surgeons may loathe working up patients for TOS, I have never met one who does not enjoy sitting at the console for a R-FRR. So why not adopt and just do it... robotically! 